\title{
Histopathologcal Effects of Methotrexate on Rat Kidney -An Experimental Study on Wistar Albino Rats.
}

\author{
Kamaldeep Singh Balowria ${ }^{1}$, Masooma Syed ${ }^{2}$, Sheikh Tousia ${ }^{3}$, NafisAhmad Faruqi ${ }^{4}$ \\ ${ }^{1}$ Medical Officer. PHC, Bhalla Doda, ${ }^{2}$ Senior Resident, Department Of Anatomy, J.N.M.C, A.M.U, Aligarh, ${ }^{3}$ MD Anatomy, ${ }^{4}$ Professor, Department Of \\ Anatomy, J.N.M.C, A.M.U, Aligarh.
}

\section{Abstract}

Introduction: Methotrexate, a folic acid antagonist is used as a first line drug for the treatment of a number of malignancies and immune disorders like rheumatoid arthritis. Due to hepatoxicity its dose needs to be monitored and sometimes it has to be stopped. In the present study we intend to do a detailed histopathological investigation after methotrexate toxicity on the relatively neglected organ i.e. kidney of rat. Subjects and Methods: Albino rats were divided into four groups (1, 2, 3, and 4) of six animals each. Control group 1 was given distilled water whereas experimental groups 2, 3, and 4 were given low, therapeutic and high doses of methotrexate orally for 28 days. Results: The results showed congestion and infiltration of the glomeruli and interstitial edema and tubular degeneration which were dose dependent. Conclusion: The degenerative changes necessitate extra precautions to be taken while using drug for prolonged period. The study merits due to great social impact.

Keywords: Methotrexate, Haematology, Rat, Experimental study.

Corresponding Author: Dr. Masooma Syed, Senior Resident, Department Of Anatomy, J.N.M.C, A.M.U, Aligarh.

Received: April 2019

Accepted: May 2019

\section{Introduction}

Methotrexate (MTX), a folic acid antagonist, is a common cytotoxic agent used in the treatment of leukemia and other malignancies. It is also used as an effective immunosuppressive and anti-inflammatory agent for treatment of some chronic inflammatory disease including psoriasis, rheumatoid arthritis, Crohn's disease. ${ }^{[1,2]}$ MTX is classified as an antimetabolite drug, as it is capable of blocking the metabolism of cells. Methotrexate competitively inhibits dihydrofolate reductase (DHFR), an enzyme that participates in the tetrahydrofolate synthesis, ${ }^{[3,4]}$ The affinity of methotrexate for DHFR is about one thousand-fold that of folate.

DHFR catalyses the conversion of dihydrofolate to the active tetrahydrofolate. Folic acid is needed for the de novo synthesis of the nucleoside thymidine, required for DNA synthesis. Folate is also essential for purine and pyrimidine base biosynthesis. Methotrexate, therefore, inhibits the synthesis of DNA, RNA, thymidylates, and proteins. ${ }^{[3]}$ Together these enzymes are responsible for the production of the main source of nicotinamide adenine dinucleotide phosphate (NADPH) in proliferating cells, thus inhibiting cell proliferation.

Cyclic high doses of MTX, as used for acute leukemia, ${ }^{[5,6]}$ or the relatively high doses of MTX used to treat severe psoriasis have been associated with hepatotoxicity, including progressive hepatic fibrosis and cirrhosis. ${ }^{[7,8]}$ MTX can additionally cause increased serum creatinine levels, uremia and hematuria, while its administration in high doses has been reported to cause acute renal failure. ${ }^{[9]}$ In the present study we have done a detailed investigation into the histopathological alteration in kidney caused by different doses of MTX in albino rats.

\section{Subjects and Methods}

The present study was carried out on Wistar strain of both sexes. The rats were procured from the "Central Animal House" of Government Medical College, Jammu.

The clearance for use of animals was obtained from "Institutional Ethics Committee" of Government Medical College, Jammu.

Table 1: Division of animals into 4 groups
\begin{tabular}{|c|c|c|}
\hline Groups & Types & Specimen numbers \\
\hline 1 & Control group & 6 \\
\hline 2 & Experimental group & 6 \\
\hline 3 & Experimental group & 6 \\
\hline 4 & Experimental group & 6 \\
\hline
\end{tabular}

\section{Experimental Design}

The animals were housed in propylene cages with dust free rice husk as bedding material where they were acclimatized for two weeks under standard laboratory condition (12 hour 
light and 12 hour darkness, temperature at $25 \pm 1 \square$ ), with ad libitum access to food and water as per the guidelines laid down by committee for both control and experimental animal.

Experimental groups were given $3 \mathrm{ml}$ of different doses (low, medium and high) of methotrexate orally for a period of 28 days. Control the Group 1 was given $3 \mathrm{ml}$ of distilled water for 28 days.

\section{Table 2: Detail of exposure of rats}

Table 2: Detail of exposure of rats
\begin{tabular}{|l|l|l|}
\hline Groups & Exposure & Dose of MTX \\
\hline Group 1 & No exposure & Distilled water \\
\hline Group 2 & Low dose & $0.25 \mathrm{mg} / \mathrm{kg}$ body weight \\
\hline Group 3 & Therapeutic dose & $0.5 \mathrm{mg} / \mathrm{kg}$ body weight \\
\hline Group 4 & High dose & $0.75 \mathrm{mg} / \mathrm{kg}$ body weight \\
\hline
\end{tabular}

\section{Dissection of the kidneys}

The animals were sacrificed after 48 hours of the administration of final dose of drugs. The rats were euthanized by keeping them in an inverted glass jar containing a large piece of cotton soaked in chloroform. The sacrificed rats were laid supine on the dissecting tray and pinned down at fore- and hind- feet in stretched out position. A midline incision was made in abdominal wall and skin was retracted to open the abdominal cavity. The intestines were displaced to one side to visualise the kidney of opposite sides. The renal vessels and ureters were ligated and cut and the kidneys removed. Tissue of $3 \mathrm{~mm}$ size was cut from kidney by using sharp blade and placed in $10 \%$ formalin solution of, the following composition. ${ }^{[10]}$

\section{Formalin: $100 \mathrm{~m}$}

II. Tap water: $900 \mathrm{~m}$

III. Sodium chloride: $8.5 \mathrm{gms}$

The tissue samples were embedded into paraffin wax and 8 um thick sections were obtained by using a rotary microtome. Haematoxylin and Eosin was used to stain the tissue sections.

\section{Results}

Severity of changes observed under microscope examination was graded as: Mild (+), Moderate (++), Severe (+++)

\section{Group 1(control)}

Sections showed normal architecture in the form of connective tissue capsule surrounding renal parenchyma which consisted of outer cortex and inner medulla. Renal corpuscles, proximal and distal convoluted tubules were seen in the cortical region. Renal corpuscles showed glomeruli within Bowman's capsule. Visceral and parietal layers of Bowman's capsules were visible along with Bowman's space. The proximal convoluted tubules were more numerous in number and were lined by a single layer of low columnar cells with apical surfaces showing brush border. The DCT were less numerous and lined by low columnar cell with wide lumen. The medullary portion contained loop of Henle and collecting tubules. The collecting tubules and ducts of Bellini were lined by cuboidal or columnar epithelium with clear, lightly stained cytoplasm and distinct cell outlines. The thin segments of loops of Henle were lined by simple squamous epithelium with central bulging nuclei. [Figure 1]

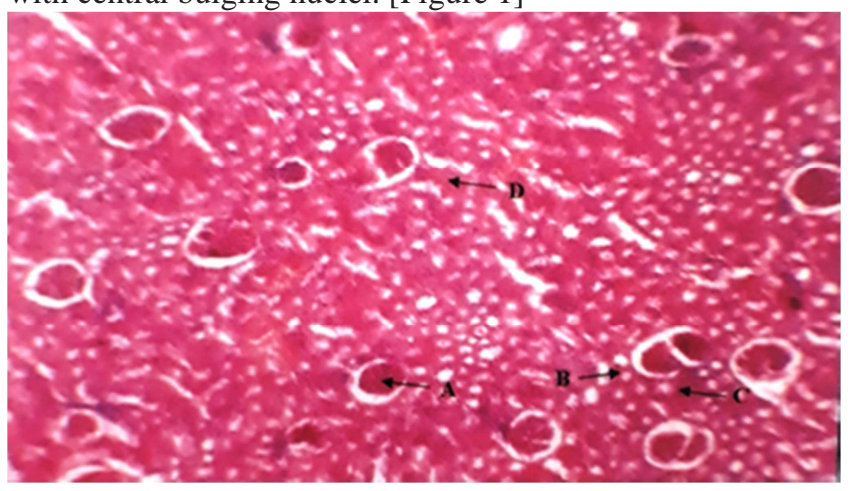

Figure 1: Photomicrograph of kidney of rats of Group 1 showing Glomeruli (A),Convoluted Tubules (B\&C) Interstitium(D) (H\&E stain 100 X)

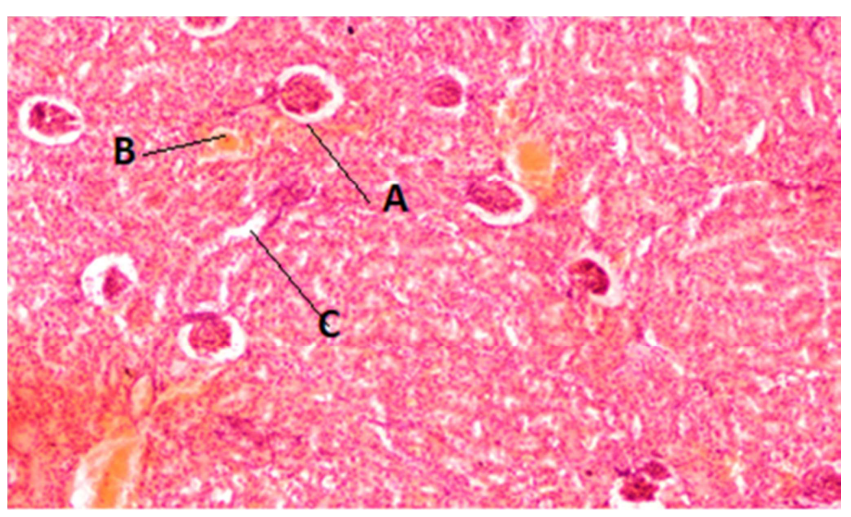

Figure 2: Photomicrograph of the kidney of rats of Group 2 showing glomerular edema (A), Vascular congestion (B) and interstitial edema. (H\&E stain 100X)

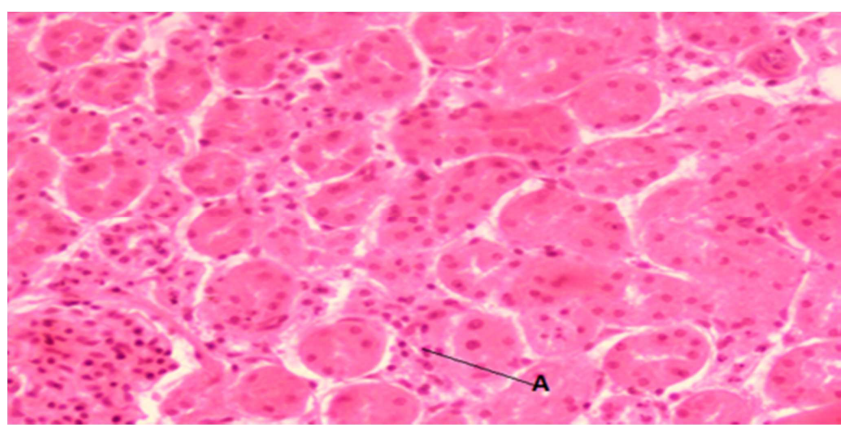

Figure 3: Photomicrograph of kidney of rats of Group 3 showing tubulitis (A). (H\&E stain $400 \mathrm{X}$ )

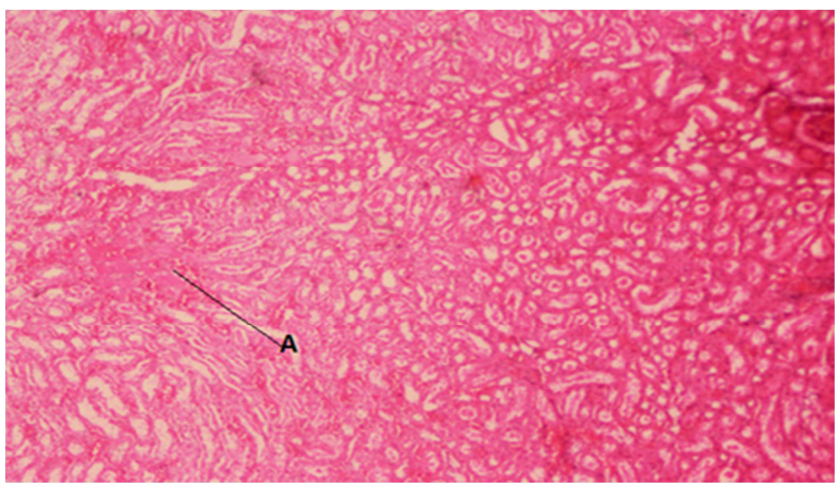

Figure 4: Photomicrograph of kidney of rats of Group 4 
showing Ischemic necrosis with areas of fresh haemorrhage (A) (H\&E stain 100X)

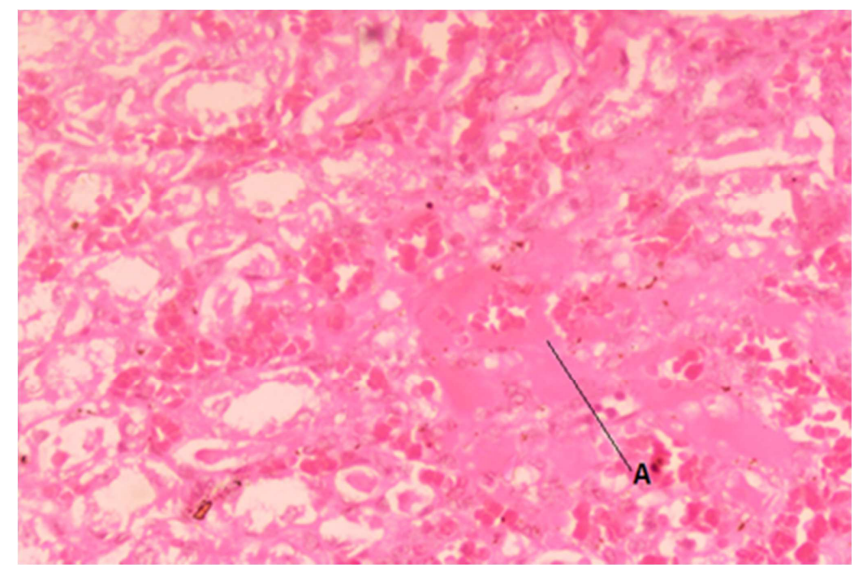

Figure 5: Photomicrograph of kidney of rats of Group 4 showing ischemic necrosis (A) (H\&E stain $400 \mathrm{X}$ )

\section{Group 2(Low dose group)}

Section of kidney of rats which received low dose of $0.25 \mathrm{mg} / \mathrm{kg}$ Body weight (B.W) showed mild (+) haemorrhage and congestion of glomeruli. The interstitium showed foci of fresh haemorrhage and edema. The tubules had dilated lumen and the lining epithelium showed vacuolar degeneration.[Figure 2]

\section{Group 3 (Therapeutic dose group)}

Section of kidney of rats given therapeutic dose of $0.5 \mathrm{mg} / \mathrm{kg}$ Body weight (B.W) showed marked congestion and haemorrhage $(++)$ in the glomeruli. Interstitial edema $(++)$ with focal infiltration of mononuclear cells in renal tubules was reported. The lumen of renal tubules was filled with red blood cells. [Figure 3]

\section{Group 4 (High dose group)}

Section of kidney of rats exposed to high dose of $0.75 \mathrm{mg} / \mathrm{kg}$ Body weight (B.W) showed marked congestion and haemorrhage $(+++)$ of glomeruli. Bowman's space was increased i.e. there was increased space between the parietal and visceral layers of Bowman's capsule with atropy of the glomeruli. Interstitium showed edema with multiple foci of ischemic necrosis of tubules. [Figure 4 \&5]

Table 3: Light microscopic changes in kidneys of rats at different doses of methotrexate.

\begin{tabular}{|c|c|c|c|c|}
\hline Changes & Group 1 & Group 2 & Group 3 & Group 4 \\
\hline \multicolumn{5}{|l|}{ 1. Glomeruli } \\
\hline a. Haemorrhage & No & Mild(+) & Moderate (++) & Severe $(+++)$ \\
\hline b. Congestion & No & Mild(+) & Moderate $(++)$ & Severe $(+++)$ \\
\hline c. Atrophy & No & No & No & No \\
\hline \multicolumn{5}{|l|}{ 2.Interstitium } \\
\hline a. Edema & No & Mild(+) & Moderate $(++)$ & Severe $(+++)$ \\
\hline b. Haemorrhage & No & Focal & - & - \\
\hline \multicolumn{5}{|l|}{ 3.Tubules } \\
\hline a. Lumen & Normal & Dilated & Dilated and filled with RBC'S & - \\
\hline b. Epithelium & Normal & Vacoular degeneration & ++ & - \\
\hline c. Infiltration & No & No & ++ & - \\
\hline d. Necrosis & No & No & No & + \\
\hline
\end{tabular}

\section{Discussion}

Even though methotrexate is an important first line drug for treatment of a number of malignancies and immune diseases, its use is limited due to hepatotoxic and the renal side effects. The mechanisms of MTX-induced renal toxicity have not been exactly established yet. However, free radicals are expected to play a role in MTX induced renal toxicity. MTX precipitates in the renal tubules, directly inducing tubular injury and induces a transient decline in glomerular filtration rate following each dose. The purpose of the present study was to evaluate the toxicity profile of the drug methotrexate histologically in wistar albino rats in order to suggest whether to modify the present therapeutic dosage of this drug for avoiding or minimising its toxicity on kidney All the experimental groups showed toxic effects on kidney which were manifested in form of congestion and haemorrhage in glomeruli. The PCT were the main site of damage and showed sloughing of epithelium, vacuolization of cells, dilated tubules and foci of chronic inflammatory cells which is in line with the report by Chelab KG et al. ${ }^{[1]}$ who found cortical tubules basophilia with infiltration of lymphocytes and congested glomeruli along with cortical areas of dilated tubules with weekly dose of $0.15 \mathrm{mg} / \mathrm{kg}$ methotrexate.

Asci $\mathrm{H}$ et al. ${ }^{[12]}$ reported similar acute methotrexate toxicity as observed in current study in the form of hydroscopic degeneration of tubular epithelial cells, focal inflammatory cell infiltration and vascular congestion. Our findings are also in concurrence with the study done by Bozkurt $\mathrm{M}$ et al. ${ }^{[13]}$ in which $\mathrm{H} \& \mathrm{E}$ sections of kidney in methotrexate treated albino rats with a single dose of $20 \mathrm{mg} / \mathrm{kg}$ B.W showed prominent degenerative changes with cell swelling, prominent nuclear loss, nuclear pyknosis of the tubular cells and infiltration of mononuclear inflammatory cells.

Our study corroborated with the work done by Patel NN et al. ${ }^{[14]}$ who observed severe congestion with vacuolar degeneration of the tubular epithelium. There was increased space between the parietal and visceral layers of Bowman's capsules along with the infiltration of mononuclear cells. Mohammed TA et al. ${ }^{[15]}$ showed changes in the kidney in the form of hydroscopic degeneration of tubules with loss of central lumen and vascular congestion after single parental dose of methotrexate $100 \mathrm{mg} / \mathrm{kg}$. It is also in accordance with the results reported by Ahmed W et al. ${ }^{[16]}$ who stated that a single intraperitoneal dose of methotrexate 


\section{Balauria et al; Ftistapathalagcal Effects of Methatrexate an Rat Kidney}

$(20 \mathrm{mg} / \mathrm{kg}$ )showed massive degenerative changes in both renal corpuscles and renal tubules. Some of the renal corpuscles appeared shrunken with atrophied glomeruli and widening of the urinary space. Moreover, marked congestion of glomeruli and cortical blood vessels with vacuolar degeneration were observed in podocytes and mesengial cells with pyknotic nuclei. The most proment feature of most examined sections was degeneration and complete loss of cellular architecture of renal tubules. The cytoplasm of most affected tubular epithelial cells showed vacuolar degeneration with pyknotic nuclei, loss of their apical brush border with marked dilatation of renal tubular lumina, focal areas of peritubular lymphocytic infiltration and interstitial edema.

The findings of present study are also similar with those reported by Dabak DO et al. ${ }^{[17]}$ which showed dilated Bowman's space, inflammatory cell infiltration, glomerular and peritubular vascular congestion and swelling of renal tubular epithelial cells. Erboga $\mathrm{M}$ et al. ${ }^{[18]}$ showed prominent degenerative changes with tubular degeneration, tubular dilatation, tubular cell swelling, cellular vacuolization, glomerular congestion and degeneration in the renal cortical tissues. These findings are in accordance with our observations which revealed chronic inflammatory foci with infiltration of cells with congestion and haemorrhage in all the three groups.

\section{Conclusion}

So the present study has clearly demonstrated that kidney get affected with methotrexate with these doses $(0.25 \mathrm{mg} / \mathrm{kg}$, $0.5 \mathrm{mg} / \mathrm{kg}$ and $0.75 \mathrm{mg} / \mathrm{kg}$ ) for 28 days and proximal convoluted tubules was the principle site of damage than distal convoluted tubule. The magnitude of these changes increases with increase in dose of methotrexate.

\section{References}

1. Uraz S, Tahan V, Aygun C, Eren F,et al. Role of Ursodeoxycholic Acid in Prevention of Methotrexate-Induced Liver Toxicity. Dig Dis Sci. 2008; 53(4):1071-7.

2. Vardi N, Parlakpinar H, Cetin A et al. Protective effect of Beta-
Carotene on Methotrexate-Induced Oxidative Liver Damage. Toxicol Pathol. 2010;38(4):592-7..

3. Rajagopalan PR, Zhang Z, McCourt L,et al. Interaction of dihydrofolate reductase with methotrexate: ensemble and singlemolecule kinetics. Proceedings of the National Academy of Sciences. 2002 Oct 15;99(21):13481-6.

4. Goodsell DS. The Molecular Perspective: Methotrexate. The Oncologist 4 1999; 4: 340-341.

5. Hersh EM, Wong VG, Henderson ES, Freirich EJ. Hepatotoxic effects of methotrexate. Cancer 1966; 19:600-606.

6. Hall PM, Jenner MA, Ahern MJ. Hepatotoxicity in a rat model caused by orally administered methotrexate. Hepatology.1991; 14:906-910.

7. Tobias H, Auerbach R. Hepatotoxicity of long term methotrexate therapy for psoriasis. Arch Intern Med 1973; 132:391-396.

8. Roenigk HH, Bergfield WF, St Jacques R, Owens FJ, Hawk WA. Hepatotoxicity of methotrexate in the treatment of psoriasis. Arch Dermatol 1971; 103:250-261.

9. Kintzel PE. Anticancer drug-induced kidney disorders. Drug Safety 2001; 24:19-38.

10. Drury RAB, Wallington EA. General Staining Procedures, Carleton's Histological Techniques, 5th edition. New York: Oxford University Press; 1980. p 125-150.

11. Chelab KG, Majeeb SK. Methotrexate induced histopathological changes in the kidneys of mice. Iraqi J Vet Sci 2009; 23(2):219222.

12. Asci H, Ozer MK, Calapoglu M, Savran M, Oncu M, Yesilot S, et al. Effects of Misoprostol on Methotrexate induced hepatic and renal damages. J Bio Life Sci 2011; 2(1):32-375.

13. Bozkurt M, Serda E, Oktayoglu P, Turkcu G, Yuksel H, Sariyildiz $\mathrm{M}$ A et al. Carvacrol prevents methotrexate induced renal oxidative injury and renal damage in rats. Clin Invest Med 2014;37(1):19-25.

14. Patel NN, Ghodasara DJ, Pandey S, Ghodasara PD, Khorajiya JH, Joshi BP, et al. Subacute toxicopathological studies of Methotrexate in Wistar Rats. Vet World 2014;7(7):489-495.

15. Mohammed TA, Al-Zubaidy AA, Khattab YI, Sahib HB. The possible protective effects of Candesartan Cilexetil against Methotrexate induced nephrotoxicity in Rabbits. Int J Adv Res 2014;2(12):315-325.

16. Ahmed W, Zaki A, Nabil T. Prevention of methotrexate induced nephrotoxicity by concomitant administration of garlic aqueous extract in rat. Turk J Med Sci 2015;45:507-516.

17. Dabak D O and Kocaman N. Effects of silymarin on methotrexate induced nephrotoxicity in rats. Ren Fail 2015;37(4):734-739.

18. Erboga M, Aktas C, Erboga Z F, Donmez Y B, Gurel A. Quercetin ameliorates methotrexate induced renal damage, apoptosis and oxidative stress in rats. Ren Fail 2015; 37(9):1492-1497.

Copyright: () the author(s), publisher. Academia Anatomica International is an Official Publication of "Society for Health Care \& Research Development". It is an open-access article distributed under the terms of the Creative Commons Attribution Non-Commercial License, which permits unrestricted non-commercial use, distribution, and reproduction in any medium, provided the original work is properly cited.

How to cite this article: Balowria KS, Syed M, Tousia S, Faruqi NA. Histopathologcal Effects of Methotrexate on Rat Kidney -An Experimental Study on Wistar Albino Rats. Acad. Anat. Int. 2019;5(1):104-107.

DOI: dx.doi.org/10.21276/aanat.2019.5.1.25

Source of Support: Nil, Conflict of Interest: None declared. 